\title{
Der Mann und seine Bäume
}

\section{Erhard Taverna}

Dr. med., Mitglied der Redaktion

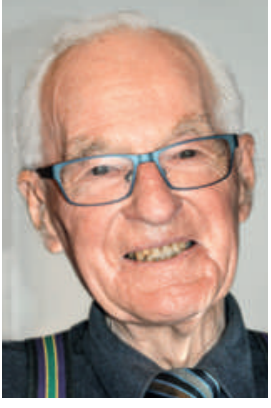

Dr. med.

Theodor Gerber
Lange Jahre hat Theodor Gerber in St. Gallen als Chirurg gearbeitet. Doch Bäume gepflanzt habe er schon in seiner Jugend, Pappeln um das Pfadfinderheim, einen Kirschbaum im eigenen Garten. Arven aufziehen ist schon eine grössere Nummer. Theodor Gerber kennt das Hochtal des Hinterrheins vom San-BernardinoPass bis Splügen von seinen Ferien bei der Grossmutter in Nufenen. Der Name «Rheinwald» erinnert an den ausgedehnten Waldgürtel, den die Walser vor rund 800 Jahren zu roden anfingen. Sie brauchten Weideland und verhütteten Eisen. Den Rest besorgten die Ziegen, so dass bis in die 1970er Jahre nur knapp hundert Baumexemplare überlebten.

Die fünfnadelige Zirbe oder Arve (Pinus cembra), romanisch Dschember, kennt jeder Alpenwanderer, der in Höhenlagen unterwegs ist. Berühmt ist der God Tamangur im Unterengadin. Ein geschlossenes Waldstück mit Lärchen und Wacholder, mitten in einer Moorlandschaft. Die Räter, als erste Talbewohner, ein semitisches Volk mit sprachlichen Wurzeln in Akkadien, haben die Namen ihrer Bäume mitgebracht. Die Bezeichnung "Arve» soll auf die arabische Wurzel hirawa zurückgehen. Viele Flurnamen im Rheinwald stammen aus dieser frühen Besiedelungsgeschichte. Eine bekannte Erzählung von Jean Giono aus den 1950er Jahren L'homme qui plantait des arbres schildert einen Mann der Provence, der im Laufe seines Hirtendaseins eine karge Berggegend in einen Eichenwald

\section{Bis tausend Jahre alt werden die langsam wachsenden Arven.}

verwandelte. Die Geschichte ist leider nur erfunden. Theodor Gerber hat sie im Laufe seines langen Lebens in die Wirklichkeit umgesetzt. Förster, Freunde, die Familie, Rekruten, Praxisassistentinnen und ihre Ehemänner, sowie unzählige weitere Freiwillige haben mitgeholfen. Sämlinge wurden in Gärten während sechs Jahren zu Jungpflanzen aufgezogen und danach in mühsamer Arbeit verpflanzt. Doch mit dem Bestocken ist es nicht getan. Ohne zwei Meter hohe Schutzgitter fressen Rehe und Rothirsche die Rinde weg. Verbissanstriche nützen wenig. Ständige Kontrollen sind nötig, weil jede Lücke zum Schlupfloch wird. Lawinen können die Zäune wegreissen. Läuse und Pilze nach
Trockenzeiten die Saftbahnen zerstören. Die vielen Reparaturen brauchen Zeit und Geld und oft wird eine zweite Anpflanzung nötig. Bis tausend Jahre alt werden die langsam wachsenden Arven, ab 70 sind sie mannbar, zu erkennen an den gelb-roten und blau-violetten Blüten, deren Pollen der Wind verbreitet. In sogenannten Mastjahren wachsen auf den erwachsenen Bäumen

\section{Über jede seiner Arven weiss er Bescheid.}

Zapfen mit je achtzig bis hundert Nüsschen. Über 80000 Arven haben private und kantonale Helfer in harter Fronarbeit angepflanzt. Teilweise wurden die Aufforstungen als Schutzwaldprojekte finanziert. Waldersatz und kleinflächige Pflanzungen von ein paar Dutzend bis zu mehreren Hundert Bäumen ergänzen den Bannwald, der zusammen mit Lawinenverbauungen die Talstrasse A13 schützen soll. Langfristig hilft der Tannenhäher, der von Arvennüsschen lebt und mit ihnen seinen Kehlsack vollstopft. Er legt tausende Depots mit fünf bis zwanzig Nüsschen an, die er selbst unter einer Schneedecke wieder findet. Zumindest den grössten Teil. Etwa ein Fünftel des Vorrates bleibt liegen und keimt an günstigen Standorten $\mathrm{zu}$ einem neuen Baum aus. Bereits sind Arven oberhalb der Waldgrenze aus diesen Verstecken gewachsen. Mit gutem Grund ist der Häher zum Signet des Nationalparks auserwählt.

Theodor Gerber ist mit seinen 88 Jahren immer noch ein aktiver Pionier. Stundenlang mäht er Farn und Gras, wo diese die Aufzucht zu ersticken drohen. Ein Netz von Informanten hält ihn auf dem Laufenden. Über jede seiner Arven weiss er Bescheid.

Von Algernon Blackwood kennen wir die unheimliche Geschichte Der Mann, den die Bäume liebten. Dort triumphieren am Ende die entfesselten Baumwesen im heulenden Sturmgebrüll, «im wilden, verzückten Tanz ihres mächtigen Astwerks». Ganz anders wird es einmal von den steilen Bergflanken tönen. Begleitet vom Ruf der Tannenhäher, rauschen dort, hoch über dem Hinterrhein, duftende Arvenwälder sanft im Wind. Gewiss lieben auch sie den Mann, der tausend Jahre früher, mit seinen zahlreichen Helfern, die ersten Sämlinge in die Hausgärten der Rheinwald-Gemeinden pflanzte und sie geduldig durch die Kinderjahre begleitete. 